- There was a small proportion of children in the UK in 2003 who were reported to have experienced some effect on their social functioning, general health or life overall as a result of their oral condition.

- The assessment of the subjective impact of oral health in the 2003 survey has enabled us to consider how children appear to be affected by their oral condition.

- On the whole, most children in the UK in 2003 appear to have been unhampered by their oral condition.

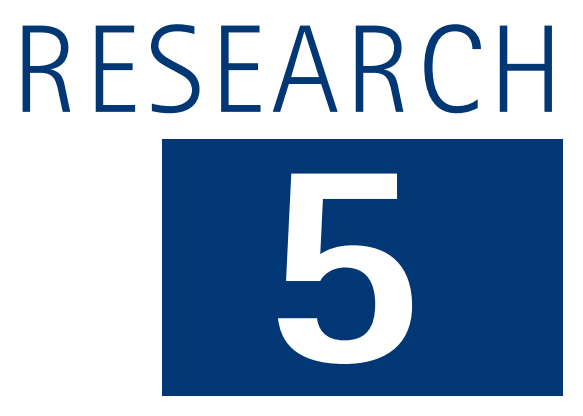

\title{
The reported impact of oral condition on children in the United Kingdom, 2003
}

\author{
N. M. Nuttall, ${ }^{1}$ J. G. Steele, ${ }^{2}$ D. Evans, ${ }^{3}$ B. Chadwick, ${ }_{1}^{4}$ A. J. Morris ${ }^{5}$ and K. Hill ${ }^{6}$
}

\section{CHILDREN'S SURVEY}

1. The dentinal caries experience of children in the United Kingdom, 2003

2. Non-carious tooth conditions in children in the UK, 2003

3. Patterns of care and service use amongst children in the UK, 2003

4. Oral health habits amongst children in the United Kingdom in 2003

5. The reported impact of oral condition on children in the United Kingdom, 2003

6. The orthodontic condition of children in the United Kingdom, 2003

Background The 2003 Children's Dental Health Survey is the fourth in a series of decennial national children's dental health surveys of the United Kingdom.

Aims This paper is concerned with how children are reported to have been affected by their oral condition during the 12 month period immediately preceding the survey and how this relates to the children's experience of caries, their dental attendance behaviour and their social class.

Method The information was gathered by self-completion questionnaire distributed to the parents of half of the sample who were clinically examined in the dental survey.

Results Some form of impact was reported by the parents of $22 \%$ of five-year-olds, $26 \%$ of eight-year-olds, $34 \%$ of 12 -year-olds and $28 \%$ of 15-year-olds. The pattern of responses to the eight impact questions was broadly similar across age groups. The most frequently reported type of impact was pain in all age groups. Impacts on oral function, selfconfidence, orally related activity and on the child's emotions were

\footnotetext{
${ }^{1 *}$ Reader in Dental Public Health \& Health Psychology, University of Dundee; ${ }^{2}$ Professor of Oral Health Sciences, University of Newcastle upon Tyne; ${ }^{3}$ Consultant in Dental Public Health, Newcastle \&t North Tyneside Health Authority; ${ }^{4}$ Reader in Paediatric Dentistry, Cardiff University; ${ }^{5}$ Lecturer in Dental Public Health, University of Birmingham; ${ }^{6}$ Lecturer in Behavioural Science, University of Birmingham

${ }^{*}$ Correspondence to: Dr Nigel M. Nuttall, Section of Dental Public Health \& Health Psychology, Dundee Dental Hospital \& School, Park Place, Dundee DD1 4HR Email:n.m.nuttall@dundee.ac.uk
}

\section{Refereed paper}

doi: 10.1038/sj.bdj.4813586

$\odot$ British Dental Journal 2006; 200: 551-555 experienced by $4-10 \%$ of children of all ages. Fewer children (1-2\%) were reported to have experienced more far reaching impacts affecting their social functioning, general health and life overall.

Conclusions Most children were reported not to have experienced any of the problems covered by the questionnaire. Of those who did, most reported a single problem and for most this was pain. Nevertheless there was a group of children for whom oral function, self-confidence, orally related activity, emotions, social functioning, their health or their life in general were reported to have been affected by their oral condition. The nature of dental care which is appropriate for such children needs to be determined.

\section{INTRODUCTION}

The way in which people are affected by their oral condition is perhaps as important as the amount or extent of oral disease they have experienced. A measure to assess the impact of oral condition was introduced into the 1998 Survey of Adult Dental Health in the United Kingdom. ${ }^{1}$ Despite there being no existing validated measures of oral impact experienced by children at the time the children's survey was being planned and undertaken, it was considered to be important to assess how children are affected by their oral condition.

Determining how children are affected by external events is difficult to evaluate, it cannot be assumed that factors which adults identify as important to children are necessarily those which actually affect children themselves. Furthermore, when dealing with children aged between five and 15 years old the nature of issues which might be associated with oral health impact (eg being teased, perceived attractiveness, functionality of the mouth) might plausibly vary with age. Furthermore, obtaining reliable information from very young children is probably beyond the scope of a self-completed questionnaire as it generally requires skilled and empathetic interviewing techniques to elicit accurate responses from them. A potential (and often, the only) solution to this is to ask people who are very close to young children for their assessment. In the case of the Children's Dental Health Survey this also seemed the only option, given that many of the other questions concerned family life and circumstances which needed to be completed by the parents or carers of the children, and that the children ranged in age from five years old to 15 years old.

In the absence of an accepted model of oral health impact specific to children we adapted the approach used in the 1998 Adult 
Dental Health Survey, which was based on a well-established model of oral health, as a framework to determine how children are affected by their oral condition. This paper is concerned with how children are reported to have been affected by their oral condition during the 12 month period immediately preceding the survey and how this relates to the children's lifelong experience of caries, their reported dental attendance behaviour and their social class.

\section{METHODOLOGY}

The 2003 survey was based on a representative sample of children aged five, eight, 12 and 15 years attending government maintained and independent schools in the UK. The survey involved 557 primary schools and 132 secondary schools. A total of 12,698 children were sampled and 10,381 were examined giving an overall response to the examination of $82 \%$.

The information for the data reported here was gathered by questionnaire distributed to a 50\% random sub-sample of the parents or carers of the children who were clinically examined. The number of items that could be devoted to the assessment of oral health impact was a consideration as the questionnaire was to be self-completed and had to be kept to an acceptable length. Also, at the time of the survey no validated or accepted measures of oral impact in children had been fully developed and tested. The 1998 adult survey used a framework developed by Slade and Spencer, ${ }^{2}$ based upon Locker's ${ }^{3}$ adaptation of the World Health Organisation's first classification of impairments, disabilities and handicaps. ${ }^{4}$ A series of seven single questions were framed to reflect the seven impact dimensions specified in the 1998 survey of adults. This involved assessing the parent's perception of the extent to which their child had been affected by oral pain and their assessment of the impact of their child's oral condition on oral function; self confidence, orally related activities; emotions; social func-

Fig. 1 The type of problem and question used to elicit whether it had been experienced in the preceding 12 months, together with the equivalent impact area assessed in the 1998 Adult Dental Health Survey.

\begin{tabular}{|c|c|c|}
\hline Type of Problem & $\begin{array}{l}\text { Question used in the survey of } \\
\text { Children's Dental Health in the } \\
\text { United Kingdom } 2003\end{array}$ & $\begin{array}{l}1998 \text { Adult Dental } \\
\text { Health survey } \\
\text { equivalent }\end{array}$ \\
\hline & In the last 12 months... & \\
\hline Pain & $\begin{array}{l}\text {... has your child had toothache or a } \\
\text { sore mouth (include painful mouth } \\
\text { ulcers or mouth infections)? }\end{array}$ & Physical pain \\
\hline $\begin{array}{l}\text { Impact on oral } \\
\text { function }\end{array}$ & $\begin{array}{l}\text {...has your child had any difficulties } \\
\text { using their teeth, gums or mouth such } \\
\text { as problems chewing or talking? }\end{array}$ & Functional Limitation \\
\hline $\begin{array}{l}\text { Impact on } \\
\text { self-confidence }\end{array}$ & $\begin{array}{l}\text {...has anything to do with your child's } \\
\text { teeth, gums or mouth made your child } \\
\text { embarrassed, self-conscious or worried? }\end{array}$ & $\begin{array}{l}\text { Psychological } \\
\text { discomfort }\end{array}$ \\
\hline $\begin{array}{l}\text { Impact on orally- } \\
\text { related activity }\end{array}$ & $\begin{array}{l}\text {...has anything to do with your child's } \\
\text { teeth, gums or mouth affected your } \\
\text { child's activities, such as causing them } \\
\text { to stop eating certain foods or playing } \\
\text { a musical instrument? }\end{array}$ & Physical disability \\
\hline $\begin{array}{l}\text { Impact on } \\
\text { emotions }\end{array}$ & $\begin{array}{l}\text {...has anything to do with your child's } \\
\text { teeth, gums or mouth affected your } \\
\text { child's emotions such as making them } \\
\text { less cheerful or more irritable? }\end{array}$ & Psychological disability \\
\hline $\begin{array}{l}\text { Impact on social } \\
\text { functioning }\end{array}$ & $\begin{array}{l}\text {...has anything to do with your child's } \\
\text { teeth, gums or mouth affected your } \\
\text { child's social life, such as stopping them } \\
\text { playing or speaking with friends? }\end{array}$ & Social disability \\
\hline $\begin{array}{l}\text { Impact on } \\
\text { general health }\end{array}$ & $\begin{array}{l}\text {..has your child's general health been } \\
\text { affected by problems with his/her teeth, } \\
\text { gums or mouth? }\end{array}$ & No equivalent \\
\hline $\begin{array}{l}\text { Impact on } \\
\text { life overall }\end{array}$ & $\begin{array}{l}\text {...was your child's life, as a whole, made } \\
\text { significantly worse because of problems } \\
\text { with his/her teeth, gums or mouth? }\end{array}$ & Handicap \\
\hline
\end{tabular}

tioning and life in general. A question about whether the child's oral condition had affected their general health was also added. The Children's Dental Health Survey questionnaire was designed for completion by the parents or carers of those who took part, although older participants (specifically the 15 year olds) may have filled the questionnaire in themselves. Therefore it was unnecessary to try to frame questions which could be answered for both very young children and for/by teenagers.

The impact questions were developed by the consortium undertaking the survey and were then tested by the Qualitative Methods Applied to Surveys (QMAS) Unit at the Office for National Statistics. The testing involved an expert review of the questions by a survey methodologist and then cognitive testing in the field. Cognitive testing explores the mental process by which respondents reach an answer to a question and aids the development of a questionnaire by suggesting unambiguous questionwording, layout and routing that respondents understand in the way the researcher intends. The final list of eight questions developed from this cognitive testing procedure and the impact areas they are intended to reflect are shown in Figure 1. The response format was based on frequency of experience in the 12 month timeframe: 1) Not at all, 2) Rarely 3) Occasionally, 4) Fairly often, 5) Very often, together with 6) Don't know to enable a parent to indicate that they could not answer the question.

Schools were unable to release the home addresses of the sampled children, in compliance with the Data Protection Act. Questionnaires were therefore sent to the participating schools in stamped envelopes for the school to address and post to the parents/carers of the selected examined children. Two reminder questionnaires were sent to non-respondents, again via the school. A slip was included with the reminder questionnaires offering parents/carers the option to have a telephone interview instead of completing the questionnaire or to phone for assistance with completing their questionnaire. One telephone interview was carried out on request.

In this paper the responses refer to experience of an oral impact in the 12 preceding months on an occasional, or more frequent, basis. The clinical information used in this paper was derived by a clinical examination of the children undertaken before answering the questionnaire. ${ }^{5}$ Obvious decay experience, referred to in the paper is the sum of teeth which, at the time of the survey examination, had decay into dentine (including teeth that were filled in the past but which needed further treatment), filled teeth, or teeth that were missing due to dental caries.

In view of the complexity of the sampling design and resultant weighting procedures, sampling errors were quantified using the statistics programme STATA, and were calculated using a design factor (deft) to take account of the complex sampling and weighting procedures. The statistical significances of differences in means and percentages between sub groups were tested by calculating the confidence interval for the differences observed, based on the standard errors calculated using the design factor. This ensured that sampling error was taken into account in the testing procedure. Where statistically significant differences between groups are reported, the 5\% threshold $(p<0.05)$ was used.

\section{RESULTS}

\section{Questionnaire response}

The survey questionnaire was distributed to half of the sample who took part in the survey. A total of 5,480 questionnaires were distributed of which 3,342 questionnaires (61\%) were finally returned (Table 1). This response was lower than in the 1993 survey when $84 \%$ of parents returned a questionnaire in the UK as a whole. The drop in questionnaire response since 1993 ranged from $12 \%$ in Scotland to $43 \%$ in Northern Ireland.

The overwhelming majority of the questionnaires that were 
Table 1 Questionnaire response in 2003, weighted base numbers and questionnaire response rate in 1993

\begin{tabular}{llllll}
\hline & England & Wales & Scotland & $\begin{array}{l}\text { Northern } \\
\text { Ireland }\end{array}$ & $\begin{array}{l}\text { United } \\
\text { Kingdom }\end{array}$ \\
\hline $\begin{array}{l}\text { \% response } \\
\text { in } 2003\end{array}$ & 65 & 62 & 68 & 45 & 61 \\
$\mathrm{~N}$ & 2962 & 1158 & 414 & 946 & 5480 \\
$\begin{array}{l}\text { \% response } \\
\text { in 1993 }\end{array}$ & 86 & 83 & 80 & 88 & 84 \\
\hline
\end{tabular}

Table 2 Proportion of children with number of reported oral condition problems experienced at least occasionally in the preceding 12 months by age (United Kingdom, 2003)

\begin{tabular}{lcccc}
\hline & $\mathbf{5}$ yr olds & $\mathbf{8}$ yr olds & $\mathbf{1 2}$ yr olds & $\mathbf{1 5}$ yr olds \\
\hline None & 78 & 74 & 66 & 72 \\
One & 13 & 16 & 22 & 17 \\
Two & 4 & 6 & 5 & 6 \\
Three & 3 & 2 & 4 & 3 \\
Four & 1 & 1 & 2 & 2 \\
Five or more & 1 & 1 & 1 & 1 \\
$n$ & 1373 & 1424 & 1374 & 1309
\end{tabular}

Table 3 Mean number and proportion of children with reported oral condition problems experienced at least occasionally in the preceding 12 months by age and sex

\begin{tabular}{llll}
\hline & $\begin{array}{l}\text { Mean number } \\
\text { of problems }\end{array}$ & $\begin{array}{l}\text { Percentage with at } \\
\text { least one problem }\end{array}$ & $\mathbf{N}$ \\
\hline Boys & & & 654 \\
5 year olds & 0.4 & 20 & 679 \\
8 year olds & 0.4 & 22 & 737 \\
12 year olds & 0.6 & 34 & 637 \\
15 year olds & 0.4 & 28 & \\
Girls & & & 719 \\
5 year olds & 0.4 & 23 & 745 \\
8 year olds & 0.5 & 29 & 638 \\
12 year olds & 0.5 & 33 & 672 \\
15 year olds & 0.5 & 28 &
\end{tabular}

returned were completed by the parents of the participants (91\%) with help from the participant in a further $9 \%$ of cases. No more than $1 \%$ of respondents indicated they were unable to answer a question on the impact of oral health by ticking the Don't know option.

\section{The reported experience of oral health impact among children}

The parents of most of the children in all age groups did not think their children had been affected by their oral condition in the preceding year (Table 2). Some form of impact was reported by the parents of $22 \%$ of five-year-olds, $26 \%$ of eight-year-olds, $34 \%$ of 12-year-olds and 28\% of 15-year-olds. The majority of those thought to have experienced an impact were only affected by one problem. Multiple types of problem were reported for only $9 \%$ of five-year-olds, $10 \%$ of eight-year-olds, 12\% of $12-$ year-olds and $12 \%$ of 15 -year-olds.

Boys and girls in each age group, except eight-year-olds, were reported to have experienced a similar number of problems (Table 3). The mean number of problems ranged from 0.4 in five-yearold boys to 0.6 in 12-year-old boys and 0.4 in five-year-old girls to 0.5 in 15-year-old girls. Among eight-year-olds a significantly higher proportion of girls (29\%) were reported to have experienced some problem during the preceding 12 months compared with eight-year-old boys (22\%). While there was a tendency to see an increase in impacts with age, this was not a linear increase with age, and problems were reported most often in 12-year-olds; $34 \%$ of 12 -year-old boys and 33\% of 12-year-old girls were said to have experienced some problem in the year preceding the survey.

The pattern of responses to the eight different impact questions

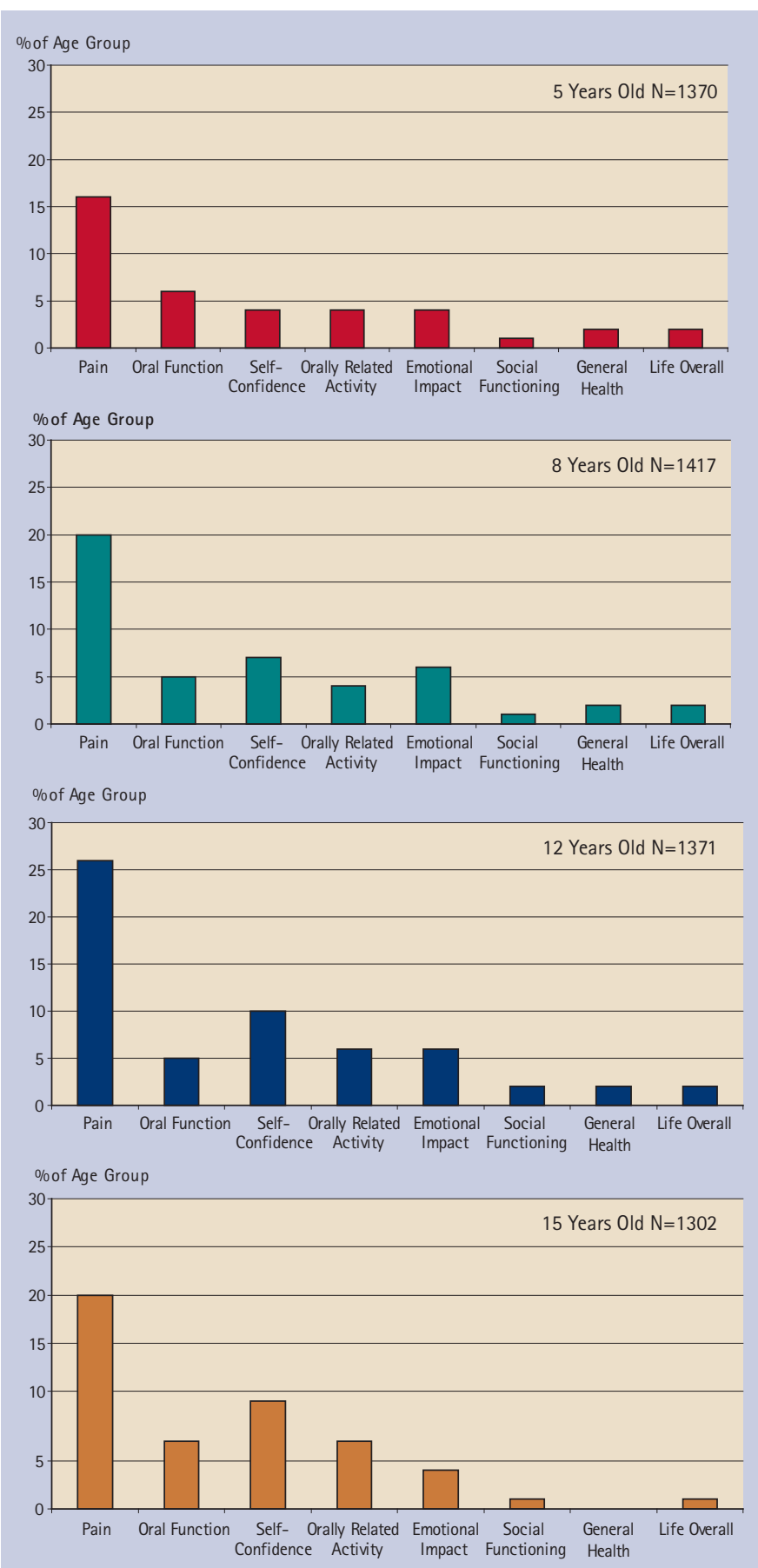

Fig. 2 The impact of oral health reported by parents as having been experienced occasionally or more often in 12 months by five, eight, 12 and 15-year-old children in the UK

was broadly similar across age groups, and the pattern can clearly be seen in Figure 2. The most frequently reported type of impact was pain in all age groups. Impacts on oral function, self-confidence, orally related activity and on the child's emotions were experienced by $4-10 \%$ of children of all ages. Fewer children (1$2 \%$ ) were reported to have experienced more far reaching impacts on their social functioning, general health and life overall. A significantly lower proportion of five-year-olds (4\%) were reported to have had their self-confidence affected occasionally or more frequently in the 12 months preceding the survey than children in any other age group. This problem was more commonly reported to affect older children; $10 \%$ of 12-year-olds and 9\% of 15-yearolds were said to have experienced some effect on their self-confidence. In some, the condition of their mouths was thought to have led to their emotional outlook on life being affected (for 
example, being less cheerful or more irritable); 4\% of five year olds, $6 \%$ of eight and 12-year-olds and 4\% of 15-year-olds were reported to have experienced some form of emotional impact as a result of their oral condition.

\section{Reported impact of oral health and dental caries}

The term 'obvious decay experience', as used here, relates to any current or past decay experience, including teeth filled or lost through decay. Among children with obvious decay experience in permanent teeth (DMFT > 0), eight year olds and 15-year-olds were significantly more likely to be reported to have experienced pain in the previous year than those of the same age without obvious decay experience (Table 4). A higher proportion of eightyear-olds with experience of obvious decay experience in their permanent teeth were also reported to have avoided particular orally-related activities; to have experienced an effect on their general health or to have had their life as a whole affected as a result of their oral condition, compared with eight-year-olds with no obvious decay experience. Twelve-year-olds with some obvi-

\begin{tabular}{|c|c|c|c|c|c|c|}
\hline & \multicolumn{3}{|c|}{ Obvious Decay } & \multicolumn{3}{|c|}{ No Obvious Decay } \\
\hline & $\begin{array}{l}8 \\
\text { yr olds }\end{array}$ & $\begin{array}{l}12 \\
\text { yr olds }\end{array}$ & $\begin{array}{l}15 \\
\text { yr olds }\end{array}$ & $\begin{array}{l}8 \\
\text { yr olds }\end{array}$ & $\begin{array}{l}12 \\
\text { yr olds }\end{array}$ & $\begin{array}{l}15 \\
\text { yr olds }\end{array}$ \\
\hline Pain & 26 & 30 & 24 & 18 & 23 & 15 \\
\hline Oral Function & 8 & 4 & 8 & 4 & 6 & 5 \\
\hline Self-Confidence & 10 & 12 & 8 & 7 & 8 & 10 \\
\hline $\begin{array}{l}\text { Orally Related } \\
\text { Activity }\end{array}$ & 9 & 6 & 7 & 2 & 6 & 8 \\
\hline $\begin{array}{l}\text { Emotional } \\
\text { Impact }\end{array}$ & 6 & 9 & 3 & 5 & 4 & 6 \\
\hline $\begin{array}{l}\text { Social } \\
\text { Functioning }\end{array}$ & 1 & 2 & 2 & 1 & 1 & 1 \\
\hline General Health & 4 & 3 & 0 & 1 & 1 & 0 \\
\hline Life Overall & 5 & 3 & 0 & 1 & 1 & 2 \\
\hline$n$ & 271 & 565 & 766 & 1153 & 810 & 543 \\
\hline
\end{tabular}

ous decay in their permanent dentition were more likely to have experienced an impact on self-confidence than 12-year-olds with no obvious decay experience in their permanent dentition.

Reported impact of oral health and dental attendance behaviour Table 5 compares the reported impact of oral health according to the attendance behaviour of the children; ie those who were reported to attend for regular check-ups compared with those who were said only to attend when they had some trouble with their teeth. Children who were described as attending for occasional dental check-ups $(\mathrm{n}=671)$ are excluded as they appeared to be a less homogenous group sometimes being either more or less affected than either of the two larger groups.

There was a clear relationship between whether a child was described as attending for regular dental check-ups or only attending when having some trouble and the reported experience of oral problems. Among eight, 12 and 15-year-olds, those seeking regular check-ups were less likely than trouble-only attendees to be reported as having experienced an orally-related impact in the preceding year. Trouble-only attendees were also more likely to be reported to have experienced oral pain occasionally or more frequently during the preceding year. Overall, 23\% of five-yearolds; $31 \%$ of eight-year-olds; $38 \%$ of 12-year-olds and 29\% of 15-year-old trouble-only attendees were reported to have had toothache or other oral pain on at least an occasional basis during the 12 months before the survey.

Other types of problem also seemed to be experienced more by children who only attend when having dental emergencies. Effects on oral function were more commonly experienced by trouble-only attendees aged eight, 12 and 15 in comparison to those of the same age who were said to attend for regular dental check-ups. Impact on self-confidence was more prevalent among eight and 12-year-old trouble-only attendees compared with those of the same age who were said to attend for regular checkups. However, the reverse was the case in 15-year-olds where a significantly higher proportion of those going for regular checkups were reported to have had their self-confidence affected compared with trouble-only attendees. A significantly higher proportion of trouble-only attendees aged eight were reported to have

Table 5 Proportion of children reported as having oral condition problems occasionally or more often in the preceding 12 months by age and child's dental attendance pattern. Multiple responses were possible

\begin{tabular}{|c|c|c|c|c|c|c|c|c|}
\hline & \multicolumn{4}{|c|}{ Regular Check-ups } & \multicolumn{4}{|c|}{ In Trouble Only } \\
\hline & $5 \mathrm{yr}$ olds & $8 \mathrm{yr}$ olds & $12 \mathrm{yr}$ olds & $15 \mathrm{yr}$ olds & $5 \mathrm{yr}$ olds & $8 \mathrm{yr}$ olds & $12 \mathrm{yr}$ olds & $15 \mathrm{yr}$ olds \\
\hline Pain & 14 & 16 & 24 & 18 & 23 & 31 & 38 & 29 \\
\hline Oral Function & 5 & 3 & 4 & 5 & 7 & 9 & 10 & 12 \\
\hline Self-Confidence & 3 & 4 & 7 & 11 & 5 & 11 & 18 & 4 \\
\hline Orally Related Activity & 4 & 2 & 5 & 7 & 4 & 10 & 9 & 8 \\
\hline Emotional Impact & 2 & 3 & 4 & 2 & 9 & 12 & 11 & 10 \\
\hline Social Functioning & 1 & 1 & 1 & 1 & 2 & 2 & 5 & 5 \\
\hline General Health & 0 & 1 & 1 & 0 & 4 & 4 & 5 & 0 \\
\hline Life Overall & 0 & 1 & 1 & 1 & 3 & 5 & 4 & 1 \\
\hline$n$ & 749 & 853 & 831 & 771 & 408 & 353 & 294 & 263 \\
\hline
\end{tabular}

Table 6 Proportion of children reported as having oral condition problems occasionally or more often in the preceding 12 months by age and household socioeconomic status. Multiple responses were possible

\begin{tabular}{|c|c|c|c|c|c|c|c|c|c|c|c|c|}
\hline & \multicolumn{4}{|c|}{ Managerial \&t Professional } & \multicolumn{4}{|c|}{ Intermediate } & \multicolumn{4}{|c|}{ Routine \&t Manual } \\
\hline & 5 yr olds & $8 \mathrm{yr}$ olds & $12 \mathrm{yr}$ olds & $15 \mathrm{yr}$ olds & $5 \mathrm{yr}$ olds & $8 \mathrm{yr}$ olds & $12 \mathrm{yr}$ olds & $15 \mathrm{yr}$ olds & 5 yr olds & $8 \mathrm{yr}$ olds & $12 \mathrm{yr}$ olds & $15 \mathrm{yr}$ olds \\
\hline Pain & 16 & 14 & 26 & 14 & 9 & 21 & 31 & 20 & 22 & 27 & 22 & 25 \\
\hline Oral Function & 6 & 2 & 5 & 5 & 4 & 4 & 6 & 11 & 5 & 9 & 5 & 8 \\
\hline Self-Confidence & 4 & 7 & 11 & 9 & 3 & 7 & 9 & 14 & 2 & 9 & 9 & 6 \\
\hline Orally Related Activity & 5 & 4 & 8 & 6 & 1 & 3 & 4 & 9 & 5 & 6 & 4 & 8 \\
\hline Emotional Impact & 4 & 3 & 8 & 5 & 0 & 7 & 3 & 5 & 8 & 8 & 6 & 3 \\
\hline Social Functioning & 1 & 2 & 2 & 2 & 0 & 0 & 0 & 0 & 1 & 1 & 1 & 1 \\
\hline General Health & 2 & 1 & 2 & 0 & 0 & 2 & 2 & 0 & 3 & 2 & 1 & 0 \\
\hline Life Overall & 1 & 1 & 3 & 1 & 0 & 2 & 1 & 1 & 3 & 4 & 2 & 0 \\
\hline$n$ & 604 & 540 & 548 & 518 & 248 & 259 & 266 & 266 & 378 & 483 & 449 & 387 \\
\hline
\end{tabular}


had any orally-related activities affected as a result of the condition of their mouth in comparison to eight-year-olds going for regular check-ups. Children in all age groups who attended for regular dental check-ups were significantly less likely to be reported to have experienced an impact on their emotions in comparison to trouble-only attendees.

At the most severe end of the impact scale, children aged five, eight and 12 who were described as attending for regular checkups were significantly less likely to be reported to have had their lives affected by their oral condition than trouble-only attendees. This severe level of impact was reported to have been encountered at least occasionally during the preceding year by $3 \%$ of five-year-olds, 5\% of eight-year-olds and 4\% of 12-yearold 'trouble-only' attendees compared with $1 \%$ or fewer of those attending for regular check-ups. This difference was not evident in 15-year-olds.

\section{Reported impact of oral health and socio-economic status}

There was some variation in the average number of problems experienced and the proportion of children affected by problems according to the socio-economic status of household, as measured by the National Statistics Socio-Economic Classification. ${ }^{6}$ Overall, five-year-olds from an intermediate background and eight-yearolds from a managerial or professional background were reported to have fewer problems than others of the same age.

Table 6 shows that a significantly lower proportion of fiveyear-olds from the intermediate occupational group were reported to have experienced pain (9\%), impact on an orally-related activity (1\%) and emotional impact (0\%) compared with those from either managerial and professional or routine and manual backgrounds. A significantly lower proportion of eight-year-olds from managerial and professional backgrounds were reported to have experienced occasional or more frequent problems with pain (14\%) and oral function (2\%) than children of the same age from other backgrounds and, compared with eight year olds from routine and manual backgrounds, a significantly lower proportion were reported to have experienced an impact on their life overall (1\%). Among 15-year-olds, a significantly higher proportion of children from routine and manual backgrounds were reported to have experienced pain (25\%) compared with the managerial and professional group and impact on self-confidence (6\%) compared to those from intermediate backgrounds (14\%).

\section{DISCUSSION}

\section{Questionnaire response}

An aspect of the questionnaire element of the survey that requires some discussion is the fall in response rate from the level achieved in the previous survey of children in 1993. A similar fall was reported for the Adult Dental Health Survey in 1998 compared with $1988 .{ }^{1}$ Some of this may be due to a growing disinclination to take part in surveys which may be related to the time and work aspect associated with participation. It is also plausible that issues concerning access to NHS dental services may lead people to be less co-operative, specifically with dental surveys, than in the past. Nevertheless, it is also likely that data protection measures that have been introduced in the past few years compromised the extent to which it was possible to follow people up directly. The rigorousness of following up non-respondents has been a notable strong point of surveys undertaken by the Office for National Statistics but the need now to ask schools to address and distribute reminders that are sent to participants may reduce the compliance with such surveys.

\section{The reported experience of oral health impact among children}

Most children were not considered, by their parents or carers to have been affected by their oral condition in the year preceding the survey. The patterns of responses were broadly similar in all four age groups.

Pain was the most frequently reported oral impact that parents were aware of in their children. There followed a group of impacts that were reported for fewer children (oral function, self-confidence, orally related activity and impact on the child's emotions), then a group of rarely encountered issues concerning social functioning, general health and life overall. The stability of the pattern of responses tends to suggest the items are detecting something similar in each age group, although it does not necessarily imply that what is being detected is a true representation of the internalised experience of impact in children. For example, the impact on a young child of poor dental aesthetics may be quite different from their parent's perception.

The finding that the patterns of responses were broadly similar in all four age groups would seem to indicate that the questionnaire captured a generalised picture of oral impact that fits children of ages five, eight, 12 and 15. On the other hand the consistency may also indicate that we may have, to some extent, tapped the parents' (adult) representation of oral impact rather than that of the child.

While the pattern of responses was similar the total extent of experience of orally related problems did differ between age groups. Twelve-year-old boys and girls were significantly more likely to be reported to have experienced an impact on their lives described by the survey questionnaire than children in the younger and older age groups. Five-year-olds were the least likely to be reported to have experienced problems and were significantly less likely to be reported to experience self-confidence issues resulting from their oral condition in comparison to older children.

\section{Reported impact of oral health and dental caries}

The impact of oral health is concerned with more than the experience of dental caries, and a relatively weak relationship between oral health related quality of life and clinical disease has been described for older adults. ${ }^{7}$ Caries is the predominant oral disease issue for children and the disease related issues may perhaps be more straightforward in children. In this study, there appeared to be an association between the children's clinically detectable experience of caries and their parents' assessment of the nature and extent of some of the problems their children had experienced, although this was not consistent in all age groups.

Between 15-23\% of children who had no obvious decay experience were reported to have suffered pain at some time during the year before they were dentally examined. The experience of pain in these groups may relate to conditions other than dental caries, such as exfoliation of primary teeth.

\section{Reported impact of oral health and dental attendance behaviour} The extent to which a person is affected by their oral health may affect the ways in which they adopt preventive health behaviours. The impact measure used in this survey asked parents whether they felt their child had been affected in particular ways by their oral health. As it is often the parent who instigates a dental visit their perception of the way in which their child is affected by their oral condition may be a critical factor in initiating a dental visit.

The relationship of measured impact with reported attendance proved to be one of the most marked relationships between impact and other aspects assessed by the survey; particularly in relation to the experience of oral pain. In addition to pain, children who were described as only attending when they had some trouble with their teeth were markedly more likely to be reported to have experienced the most severe forms of impact such as their social functioning (among 12 and 15-year-olds) and health and 
life in general (among five, eight and 12-year-olds). Whilst the implications of this would seem to be that regular visits are associated with fewer adverse impacts of oral health problems on day to day life, and this would seem to be borne out by the data reported for caries, there is also a potential circular explanation for this which should be considered. Parents whose children only attend when they have some trouble with their teeth might, as a result, have a more thorough understanding and awareness of their children's oral problems and be more likely to report an impact than parents whose children go for dental check-ups.

\section{Reported impact of oral health and socio-economic status}

There was some variation in the average number of problems experienced and the proportion of children affected by problems according to the socio-economic status of household but these did not consistently take the form of a gradient across the socioeconomic groups.

\section{The experience of multiple and severe impact}

Although the experience of multiple impacts by children $6 \%$ or fewer) and the experience of the most severe forms of impact was comparatively rare ( $2 \%$ or fewer) in each age group, their existence represents a challenge for dental services. More of these children appear to only attend when they have some trouble with their teeth and to have experienced more dental caries than children who are reported to have experienced one or no impacts. There is a need to define and understand the needs of these particular children associated with attendance behaviour (behavioural needs) and clinical services (care needs). The clinical care workload represented by the existence of these groups is potentially greater in proportional terms to that of children who are not so affected by their oral condition. The nature of dental care which is appropriate for such children needs to be determined as do the barriers specific to their dental attendance.

\section{CONCLUSIONS}

Most children were reported not to have experienced any of the problems covered by the questionnaire. Of those who did experience a problem, most were only reported to have experienced a single problem and for most this was the experience of pain. Nevertheless there was a group of children who were said to have had their oral function, self-confidence, orally related activity, emotions, social functioning, their health or their life in general affected by their oral condition. The nature of dental care which is appropriate for such children needs to be determined.

This work was undertaken by a consortium comprising the Office for National Statistics and the Dental Schools of the Universities of Birmingham, Cardiff, Dundee and Newcastle and the Dental Health Services Research Unit, Dundee who received funding from the United Kingdom Health Departments; the views expressed in this publication are those of the authors and not necessarily those of the Health Department.

1. Kelly M, Steele J, Nuttall N et al. Adult Dental Health Survey - Oral Health in the United Kingdom 1998. London: The Stationary Office, 2000.

2. Slade G D, Spencer A J. Development and evaluation of the Oral Health Impact Profile. Comm Dent Health 1994; 11: 3-11.

3. Locker D. Measuring oral health a conceptual framework Comm Dent Health 1988: 5:5-13.

4. World Health Organisation. International Classification of Impairments, Disabilities and Handicaps. Geneva: WHO, 1980.

5. Pitts N B, Chestnutt I G, Evans D etal. The dentinal caries experience of children in the United Kingdom, 2003. Br Dent J2006: 200: 313-320.

6. Rose D, Pevalin D J (Eds.) A Researcher's Guide to the National Statistics Socioeconomic Classification. London: Sage Publications, 2003.

7. Locker D, Slade G. Association between clinical and subjective indicators of oral health status in an older population. Gerodontology 1994: 11: 108-114. 